\title{
FROM RAMCET TO AMSET
}

\author{
Colonel R. S. HUNT, M.B.E., F.R.C.S.(Edin.)
}

IN 1962 an article entitled "Introducing the RAMCET" appeared in this Journal (Vol. 108, p.35). It was the first published record of a fully equipped emergency trolley produced and in use. At that time the Americans were producing " The Crash Cart" and the teaching hospitals in Britain were developing the cardiac arrest trolley, knowing that emergencies can and do occur in any part of the hospital apart from the emergency ward or operating theatre, even in the corridors or stairways. The RAMSET was not only the first, it was the first fully equipped trolley capable of dealing with any likely emergency. It is four years since the idea was born and two since the first working prototype was produced and described in the article referred to above. This is a short account of what has happened since.

It became clear that the original model was unwieldy and over-loaded. Experience and many discussions have resulted in the present model, now known as the AMSET, being short for Army Medical Services Emergency. Trolley. It is equipped to deal withcardiac arrest, respiratory failure or difficulty, severe shock and fluid loss, which after all are the three main conditions needing immediate treatment.

The illustrations describe the AMSET better than words and the list of equipment in the handbook issued with the trolley indicates the accessories to the main items shown in the drawings. The AMSET is shortly to be supplied to selected hospitals, each with a handbook on its use.

Special features of the AMSET are :-

The Airways Box:

The Cardiac Arrest Board: forming the cover to one side of the trolley and easily

The Folding Table:

The Flexipoise Lamps:

The Universal Plug: detachable and slipped under the patient, thus avoiding the need to lift him onto the floor.

which is reached from either side of the trolley and can be carried ahead of it should there be delay or difficulty in getting the trolley upstairs.

forming the cover to the opposite side of the trolley and providing extra working surface.

with magnetic feet able to grip any nearby metal bar or ledge, e.g. a Balkan beam or bedhead.

able to fit any variety of socket. The four sockets on the trolley itself allow any of the electrical equipment to be used without any further wall sockets.

Two points need emphasis:-

(1) The equipment on the AMSET is that considered absolutely necessary to start treatment. It is not intended to contain all the needs for every kind of therapy. This is available in all hospitals and can be collected when time permits. 
(2) Experience has shown that there is some reluctance to use the AMSET because it appears complicated. Once used it soon becomes indispensable and it is suggested that it be used on some "cold" cases to begin with to let the staff become familiar with its use and its advantages.

Each AMSET is to be issued with:-

(a) A Handbook on its use.

(b) A copy of the Instruction Sheet used at the Cambridge Military Hospital relating to its place of keeping and method of calling it forward.

(c) A comprehensive list of equipment.

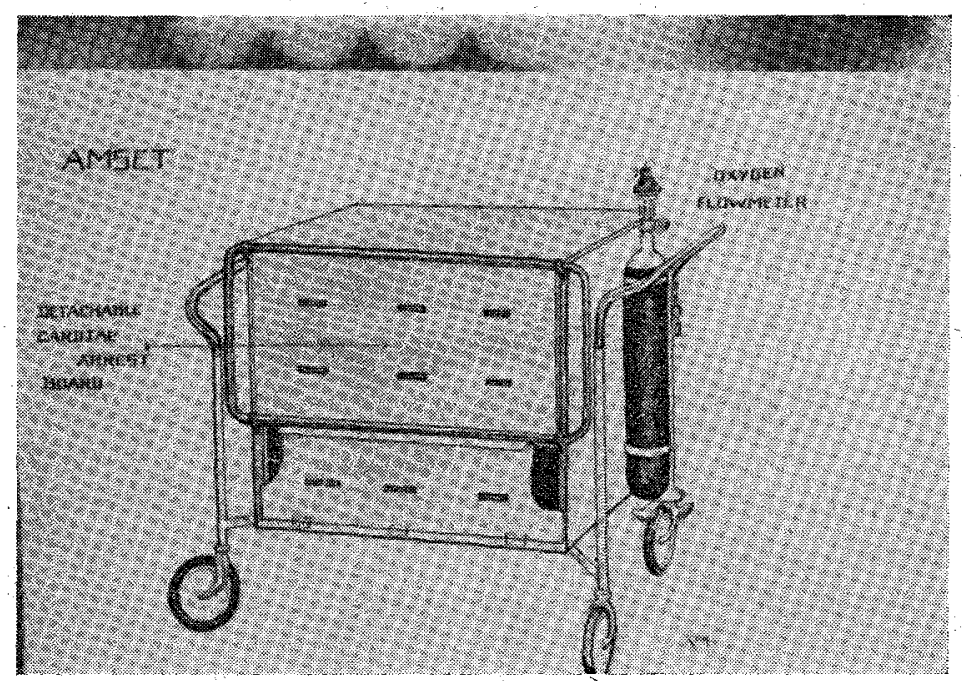

Fig. 1

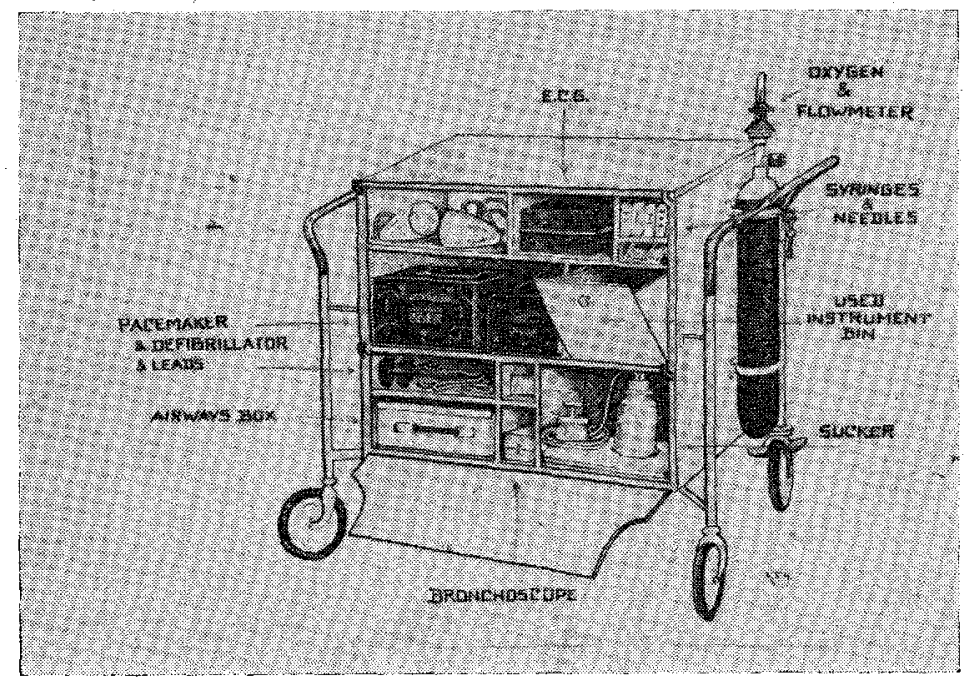

Fig. 2 


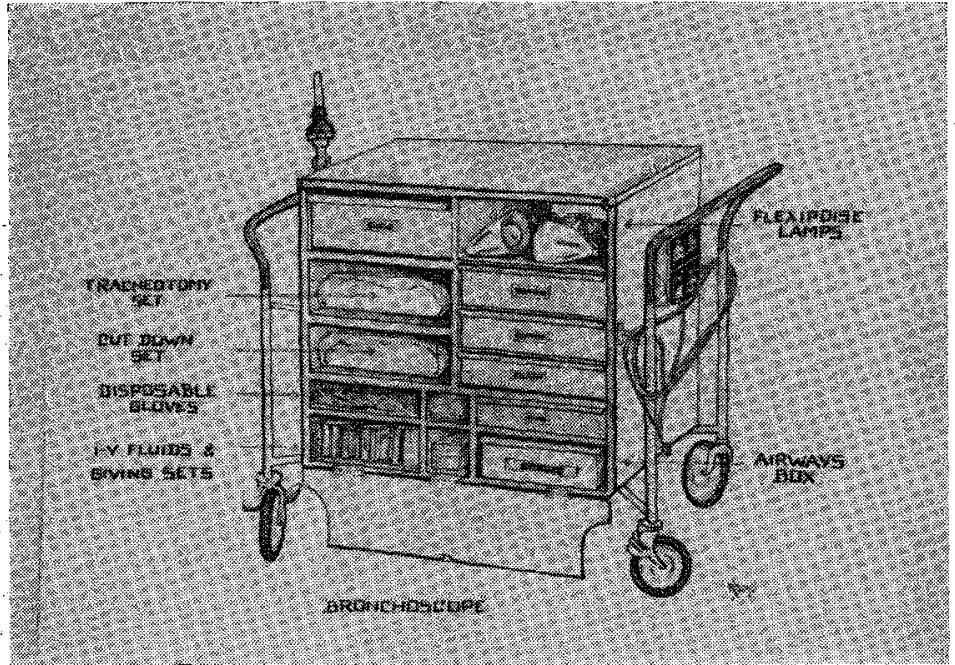

Fig. 3

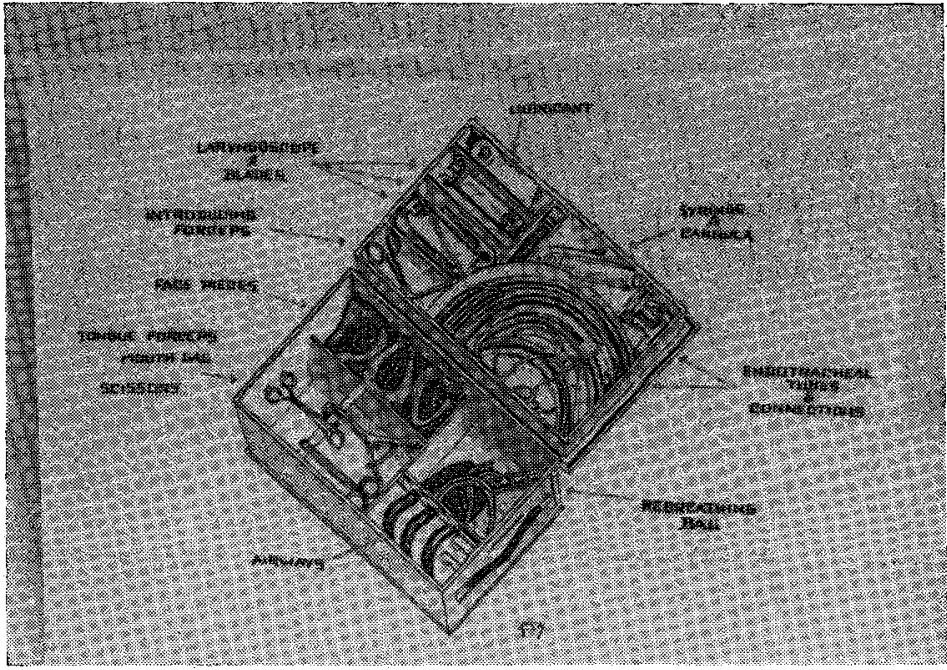

Fig. 4

From The New Years Honours

O.B.E. Lieutenant-Colonel W. O'Brien, M.D., M.R.C.P., R:A.M.C.

M.B.E. Major (QM) J. F. Davey, R.A.M.C. (T.A.); Captain (local Major) M. C. Wootton, M.B., R.A.M.C. 